\title{
Comentarios al decreto-ley 5/2012 de medidas urgentes en materia urbanística y para la protección del litoral de Andalucía ${ }^{1}$
}

\author{
José Zamorano Wisnes \\ Profesor Asociado, Facultad de Derecho \\ Universidad de Huelva
}

\begin{abstract}
SUMARIO: I. CONSIDERACIONES GENERALES.II. LA UTILIZAGIÓN DE LA TÉGNIGA DEL DEGRETO-LEY. III. LA PROTECGIÓN DEL LITORAL. 1. Las Directrices Regionales de Ordenación del Litoral de Andalucía. 2. El POTA y los POT de ámbito subregional. 3. El Plan de Protección del Corredor Litoral de Andalucía. A. Objetivo, ámbito y contenido. a) Objetivo. b) Ámbito. c) Contenidos materiales. B. Procedimiento. C. Medidas cautelares. IV. LA ADAPTAGIÓN DEL PLANEAMIENTO MUNICIPAL AL POTA. V. BIBLIOGRAFÍA
\end{abstract}

\section{RESUMEN}

El presente artículo aborda el estudio del Decreto-Ley 5/2012, de 27 de noviembre, de medidas urgentes en materia urbanística y para la protección del litoral de Andalucía, que modifica la Ley de Ordenación del Territorio (LOTA) para introducir un nuevo plan territorial, el Plan de Protección del Corredor Litoral (PPCLA), heredero en cierto modo de las Directrices de Ordenación del Litoral de Andalucía y con el que se pretende la ordenación unitaria del litoral.

El estudio analiza sus objetivos, ámbito, contenidos materiales, procedimiento de aprobación y la medida cautelar de suspensión de determinados planes parciales cuyo ámbito territorial se encuentre en la zona de influencia prevista en el Decreto Ley. También se ocupa de la modificación de la LOTA que lleva a cabo el Decreto-Ley, con la finalidad de aclarar el carácter prevalente del Plan de Ordenación del Territorio de Andalucía sobre el planeamiento municipal y los mecanismos establecidos para que éste se adapte a aquél. Así mismo, se estudia la adecuación del Decreto-Ley 5/2012 a los presupuestos que legitiman la utilización de una norma de esta naturaleza, lo que arroja una valoración negativa que conduce a abogar por su tramitación como proyecto de ley.

\footnotetext{
${ }^{1}$ Este trabajo se ha realizado en el marco del Proyecto de Excelencia de la Junta de Andalucía "Ordenación y gestión integradas del litoral en Andalucía” (SEJ-4770)
} 
El estudio concluye que el PPCLA tendrá un impacto significativo en nuestro litoral, tanto en lo que se refiere a la ordenación del mismo como en lo que concierne al ius aedificandi de los propietarios de los suelos incluidos en la zona de influencia de la Ley de Costas cuya calificación actual sea la de suelo no urbanizable (SNU), suelo urbanizable sectorizado o suelo urbanizable no sectorizado, puesto que su conservación conllevará su "congelación" o reclasificación como SNU y, consecuentemente, la limitación de la capacidad edificatoria de los mismos e, incluso, la de algunos usos más agresivos, todo ello con la finalidad de mantener los suelos en un estado próximo al natural.

Palabras clave: Decreto-Ley; litoral; gestión integrada; gestión ecosistémica; conservación; POTA; planeamiento municipal.

\section{ABSTRACT}

This paper addresses the study of the Decree-Act, of November the $27^{\text {th }}$, which enacted urgent measures on urban planning matters and on the protection of the Andalusian coastline. This decree modified the previous Act of Land-Use Planning (known as LOTA in Spanish) in order to set up a new territorial plan called Plan for the Protection of the Coastal Corridor (known as PPCLA in Spanish). This plan can be seen as an inheritor of the Guidelines for the Planning of the Andalusian Coastline, whose aim was an unified arrangement of the seashore.

This study analyses the objectives of the Decree, its territorial scope, its contents, its procedure of approval and the temporary suspension of those partial plans affected by the territorial scope foreseen in the Decree-Law. planThis study also deals with the modification of the Act of Land-Use Planning carried out by the Decree. This modification is aimed to make clear the prevalent character of the Andalusian Land-Use Plan over any local planning and the correct adaptation of the latterto the Decree - Law 5/2012. Furthermore, the paper addresses the adequacy of the Decree to the principles that enable the use of that kind of norm. In this sense, the use of Decree-Law for such regulation deserves a negative assessment and justifies, indeed, its enactment as a parliamentary act.

The study concludes that the Plan for the Protection of the Coastal Corridor will have a significant impact in our coastline, regarding the coastal planning. Also the "right to build" of land owners included in the scope of the Coast Act and currently designated as "non-developmental lands", "developable sectorized lands" and "non-sectorized developable lands" will be affected by the Decree. This is so because its conversion could entail their 
reclassification as non-developmental areas and, therefore, limits for future buildingon them and, even, a restriction for more aggressive uses. The sole aim of this new regulation is to maintain the lands in an status as similar as possible to the natural and original one.

Key Words: Decree - Law, coastline, integrated management, ecosystemic management, conservation, POTA (Andalusian Land-Use Plan), local planning.

\section{GONSIDERACIONES GENERALES}

El contenido de la norma objeto de estos comentarios, el Decreto-Ley 5/2012, de 27 de noviembre ${ }^{2}$, de medidas urgentes en materia urbanística y para la protección del litoral de Andalucía, es breve, apenas tres artículos, una disposición adicional, una transitoria y diez disposiciones finales, aún cuando, como se verá, con una impronta apreciable y no exentos de polémica. El primero de los artículos del Decreto-Ley crea la figura del Plan de Protección del Corredor Litoral de Andalucía (PPCLA) como instrumento de la planificación territorial, para ello modifica el artículo 5.1 de la Ley de Ordenación del Territorio de la Comunidad Autónoma de Andalucía (LOTA) ${ }^{3}$ e incorpora un nuevo nuevo título, el VII, y anexo a la citada Ley. Con este artículo, también, se modifica la primitiva redacción del artículo 22.1 de la LOTA, clarificando la prevalencia del POTA sobre el planeamiento municipal.

En el segundo de los preceptos del Decreto-Ley se adoptan medidas cautelares en relación con el planeamiento de los municipios litorales cuyos ámbitos incluyan suelos urbanizables situados en la zona de influencia y su planeamiento general sea anterior al POTA.

El artículo tercero establece plazos para que los planes generales de los municipios de Andalucía adapten sus determinaciones al POTA, prohibiendo la tramitación de los instrumentos de desarrollo de dichos planes para el supuesto de que la demandada adaptación no se produzca.

La disposición adicional dispone el plazo para elaborar el PPCLA y, una

\footnotetext{
${ }^{2}$ El Decreto Ley 5/2012 ha sido convalidado Acuerdo del Pleno del Parlamento de Andalucía en sesión celebrada el día 12 de diciembre de 2012 publicado por Resolución de la Presidencia del Parlamento de Andalucía de 12 de diciembre de 2012 (BOJA 28/12/2012)

${ }^{3}$ Ley $1 / 1994$, de 11 de enero.
} 
singularidad de procedimiento, al ordenar que el plan se someta a información pública en un plazo de seis meses desde el decreto de formulación.

La disposición transitoria regula el régimen de derecho transitorio para la tramitación de los planes urbanísticos que se vean afectados por las modificaciones introducidas por las disposiciones finales primera a octava.

Por último, las disposiciones finales primera a octava modifican, unificando, los plazos establecidos por las distintas leyes sectoriales de la CAA para que las Administraciones sectoriales emitan informe en el procedimiento de aprobación de los instrumentos de planeamiento urbanístico.

Por tanto, en la norma estudiada se contienen tres grupos de medidas claramente diferenciables, aún cuando, en ocasiones unas y otras se relacionan: por un lado aquellos preceptos que tienen por finalidad la creación de una nueva figura de planeamiento territorial, cuyo objeto es la mejora de la protección del litoral; en segundo lugar el establecimiento de plazos a fin de conseguir la adaptación del planeamiento municipal al POTA y, por último, las Disposiciones Finales cuya función no es otra que agilizar la tramitación del planeamiento municipal mediante la modificación de la normativa sectorial andaluza.

\section{LA UTILIZAGIÓN DE LA TÉGNICA DEL DEGRETO LEY}

Para la elaboración de la norma enunciada el Gobierno andaluz utiliza la técnica legislativa del Decreto-Ley que justifica, una vez más, "en el contexto de grave crisis económica", resulta sorprendente la pobreza de argumentos que tal justificación entraña, con la que se priva al Parlamento de su principal función: legislar ${ }^{4}$.

En las líneas siguientes vamos a centrarnos en el estudio de los presupuestos habilitantes necesarios para poder utilizar este tipo normativo para, a continuación aplicarlas al Decreto-Ley comentado, si bien, dejamos apuntado, desde este momento las dudas que nos ofrece su utilización en relación con las medidas normativas adoptadas en el Decreto-Ley 5/2012.

El Estatuto de Autonomía para Andalucía dispone en su artículo 110.1 que "En caso de extraordinaria y urgente necesidad el Consejo de Gobierno podrá

${ }^{4}$ Aún cuando se trata de una obviedad, puede verse en este sentido la STC 1/2012 (FJ $\left.9^{\circ}\right)$. 
dictar medidas legislativas provisionales en forma de decretos-leyes, que no podrán afectar a los derechos establecidos en este Estatuto, al régimen electoral, ni a las instituciones de la Junta de Andalucía. No podrán aprobarse por decreto-ley los presupuestos de Andalucía". Como puede observarse el artículo citado reproduce, casi literalmente, el artículo $86 \mathrm{CE}$, por lo que en el estudio de los presupuestos habilitantes nos centraremos en la jurisprudencia constitucional y doctrina que han estudiado éste.

Los presupuestos habilitantes necesarios para la utilización de la técnica del Decreto-Ley son un concepto jurídico indeterminado ${ }^{5}$, como ha puesto de manifiesto, de forma mayoritaria por la doctrina. Tasado por la doble adjetivación de una necesidad que a la vez sea extraordinaria y urgente, como mantiene Salas ${ }^{6}$, es preciso que se produzca una circunstancia extraordinaria, lo que supone una valoración cualitativa de la necesidad y, urgente al mismo tiempo, de modo que sí, ésta admite dilación, sin perjuicio grave de su eficacia, o dicho de otro modo, cuando la situación pueda razonablemente esperar a ser regulada por una Ley votada en el Parlamento, no es posible la utilización del DecretoLey $^{7}$.

La jurisprudencia constitucional ha optado por una solución flexible y matizada, de modo que se acude a esta solución normativa como una posibilidad no traumática ${ }^{8}$, si bien en el proceso, como afirma Pulido Quevedo, ha terminado por convertir el presupuesto habilitante en un concepto jurídico indeterminado de muy poca eficacia para el control del ejercicio indebido del Decreto Ley. Así, a título de ejemplo pueden citarse las sentencias 189/2005;

${ }^{5}$ La posición mayoritaria está representada, entre otros, por Salas Hernández, J. (1979), página 30; Muñoz Machado, S (2006), página 640; Medina Guerrero, M. (2010), página 285 o Herráiz Serrano, O (2011), página 113. Frente a dicha tesis, Morillo-Velarde Pérez, JI (1989), página 830, mantiene que se trata de "discrecionalidad" de muy difícil control siempre que no se haga un uso arbitrario. Una posición similar mantiene Rebollo Puig, M. (2008), páginas 177 y 178 al afirmar que más que concepto jurídico indeterminado estamos en presencia, cuando menos tal y como se ha interpretado por la jurisprudencia constitucional, de una potestad discrecional, la posición de estos dos últimos autores se vería avalada por la ductilidad con que la jurisprudencia constitucional ha interpretado los presupuestos habilitantes, de los que se ha dicho que el "juicio puramente político de los órganos a los que incumbe la dirección del Estado" tiene un peso importante en la apreciación de dichas circunstancia, afirmando a continuación que no se trata de una cláusula vacía de significado dentro de la cual el lógico margen de apreciación política del Gobierno se mueva libremente sin restricción alguna, sino, por el contrario, la constatación de un límite jurídico a la actuación mediante decretos-leyes (SSTC 31/2011; 137/2011; 1/2012; 39/2013)

${ }^{6}$ Salas Hernández, J. (1979), página 30, En igual sentido Astarloa Huarte-Mendicoa, I. (1985), página 118, o Barreiro González, G.J. (2003), páginas 52 y 54.

${ }^{7}$ Núñez Lozano, M.C. (2003), páginas 350 y 351.

${ }^{8}$ En tal sentido Barreiro González, G.J (2003), páginas 47 y 48. 
329/2005; 68/2005 o más recientemente 137/2011 y 237/2012. En ellas el Tribunal estudia lo que de extraordinario debe tener la situación que se pretende modificar, al afirmar, que "nuestra Constitución ha adoptado una solución flexible y matizada respecto del fenómeno del Decreto-Ley (...) ni se limita a permitirlo de una forma totalmente excepcional en situaciones de necesidad absoluta, de modo que la utilización de este instrumento normativo se estima legitima en todos aquellos casos en que hay que alcanzar los objetivos marcados por la gobernabilidad del país (...)"9, poniendo, en consecuencia, el acento del control de constitucionalidad en el adjetivo "urgente", de esta forma, se ha mantenido que el fin que justifica la legislación de urgencia no es otro que subvenir situaciones concretas de los objetivos gubernamentales que por razones difíciles o imposibles de prever, requieren una acción normativa inmediata en un plazo más breve que el requerido por la vía normal o por el procedimiento de urgencia para la tramitación parlamentaria de las leyes o en que las coyunturas económicas exigen una rápida respuesta ${ }^{10}$.

Centrados en la "urgencia", es preciso que exista la necesaria adecuación entre las medidas adoptadas en el Decreto-Ley y la situación de hecho que se pretende corregir de modo que, seguimos en este punto a Ramallo Massanet ${ }^{11}$, es imprescindible que se den los siguientes requisitos: a) que las medidas mantengan relación directa o indirecta con la situación que se trate de afrontar ${ }^{12}$; b) que la medida modifique de manera instantánea la situación jurídica existente; c) que la medida no consista en una deslegalización que difiera al futuro la regulación por el Gobierno de la materia deslegalizada; d) que la medida no afecte a la estructura del ordenamiento; e) la permanencia de las medidas adoptadas por vía de Decreto-ley tienen siempre carácter provisional, en tanto no se conviertan en una ley formal ordinaria ${ }^{13}$.

La enumeración de los presupuestos ha de completarse, añadiendo, la necesidad de motivar, suficientemente, la existencia del presupuesto de hecho habilitante lo que no se satisface con formulas estereotipadas ${ }^{14}$ pues como, afirma el Tribunal Constitucional, aquélla tiene que ser "explícita y razonada", y

\footnotetext{
${ }^{9}$ Véase además de las sentencias citadas las 11/2002 (FJ 4 $\left.{ }^{\circ}\right) ; 137 / 2003\left(\mathrm{FJ} \mathrm{3}^{\circ}\right)$.

${ }^{10} \mathrm{SS} 5 / 1983\left(\mathrm{FJ} \mathrm{3}^{\circ}\right) ; 137 / 2011\left(\mathrm{FJ} 4^{\circ}\right)$.

${ }^{11}$ Ramallo Massanet, J. (2003), páginas 435 a 437. Véase en sentido similar en relación a la inmediatez y la innovación del ordenamiento jurídico Rebollo Puig, M. (2008), páginas 180 y 181.

${ }^{12}$ Véase las SSTC 11/2002, FJ 6; 68/2007 FJ 8, 1/2012 FJ 6 o 39/2013 FJ 5.

${ }^{13}$ Salas Hernández, J. (1979), página 42, mantiene que la provisionalidad del Decreto-Ley se afirma en tanto técnica de manifestación de voluntad y no de su contenido.

${ }^{14}$ SSTC 332/2005; 137/2011.
} 
existir "una conexión de sentido o relación de adecuación entre la situación definida que constituya el presupuesto habilitante y las medidas" que en la norma se adopten. El examen de la concurrencia de estos requisitos ha de deducirse de la valoración conjunta de la exposición de motivos de la norma, a lo largo del debate parlamentario de convalidación y en el propio expediente de elaboración de la misma ${ }^{15}$.

Examinemos pues, las medidas legislativas concretas aprobadas por el Decreto-Ley 5/2012, para aproximar, si se quiere de forma indiciaria, una respuesta positiva o negativa a la cuestión planteada del cumplimiento por parte del mismo de los presupuestos habilitantes y, fundamentalmente, a la situación de urgencia definida.

La primera medida consiste, como vimos, en crear un nuevo instrumento de planificación territorial: el PPCLA, para cuya aprobación se concede el Ejecutivo legislador un plazo de dos años a contar desde la entrada en vigor del Decreto-Ley, plazo que podrá ser ampliado, si bien excepcionalmente (Disposición Adicional Única); debiendo de someterse el Plan a información pública en un plazo de seis meses desde que se apruebe el decreto de formulación (Disposición Adicional) ${ }^{16}$, con lo que se están sentando las bases para "un desarrollo económico sostenible a medio y largo plazo" (Comparecencia del Consejero de Agricultura, Pesca y Medio Ambiente $)^{17}$. En consecuencia ¿donde está la urgencia? ¿cómo es posible sostener que en plazos menores no se puede tramitar una ley por procedimiento de urgencia? Veamos un ejemplo: el BOPA de 3 de julio de 2012 publica el Proyecto de Ley 9-12/PL-0000002, por el que se modifica la Ley 9/2007, de 22 de octubre, de la Administración de la Junta de Andalucía ${ }^{18}$, pues bien, dos meses y medio después, el 19 de septiembre publicaba el BOPA el acuerdo de Pleno de aprobación de la Ley, y el 1 de octubre, se publicaba en el BOJA la modificación de la Ley de Administración de la Junta, es decir un plazo de tres meses, la mitad del plazo que se concede el Gobierno andaluz para iniciara el periodo de información pública del PPCLA.

\footnotetext{
${ }^{15}$ SSTC 29/1982 (FJ 3 ${ }^{\circ}$ ); 68/2007 (FJ 6 $\left.{ }^{\circ}\right) ; 137 / 2011\left(\mathrm{FJ} \mathrm{4} 4^{\circ}\right) ; 237 / 2012\left(\mathrm{FJ} 4^{\circ}\right)$.

${ }^{16}$ Estos plazos fueron reiterados por el Consejero de Agricultura, Pesca y Medio Ambiente en su comparecencia ante el Pleno del Parlamento Andaluz en el debate previo a la convalidación del Decreto Ley $5 / 2012$, llegando a afirmar que "Se va a hacer un gran esfuerzo por acelerar la elaboración de este plan, por redactarlo en un plazo de seis meses ...//.." (DSPA número 23).

${ }^{17}$ Ibídem.

${ }^{18}$ Este Proyecto de Ley procede de la Convalidación del Decreto-Ley 2/2012.
} 
En otra línea argumental, y haciéndonos eco, de la jurisprudencia constitucional sobre medidas como la adoptada, el Tribunal Constitucional ha mantenido que, para hacer frente a una situación de extraordinaria y urgente necesidad, las medidas adoptadas han de ser concretas y de eficacia inmediata y, por tanto, dado su carácter no pueden alterar la estructura del ordenamiento (SSTC 29/1982, FJ 6º 1/2012 FJ 12), y debe existir una conexión de sentido entre la situación definida que constituya el presupuesto de hecho y las medidas que se adoptan.

Pues bien, la medida legislativa comentada, ni es urgente, ni es concreta, su eficacia se dilata a varios años después de la aprobación del Decreto-Ley y no se acierta a adivinar la relación existente entre la "grave crisis económica" (presupuesto habilitante) y la medida que venimos comentando: creación de un nuevo plan territorial, que, ciertamente, permitirá intervenir en el ámbito del litoral pero ni se dice, ni se intuye, como ello va a contribuir a superar o hacer menos gravosa para los ciudadanos la "grave crisis económica", ni siquiera como va a contribuir a crea un nuevo modelo turístico en Andalucía.

La segunda de las medidas legislativas consiste en dar nueva redacción al artículo 22.1 de la LOTA, aclarando que el POTA también es vinculante para los planes municipales. Mis reticencias en relación con la misma son de dos tipos: en primer lugar, como justificaré más adelante esta modificación no hace sino reiterar la previsión del artículo 21.2 LOTA con lo que mal puede predicarse de la misma el carácter de extraordinaria y, mucho menos, de urgente. En segundo lugar, y teniendo en cuenta que el POTA fue aprobado por Decreto 206/2006, de 28 de diciembre y publicado en el BOJA de 29 de diciembre, parece difícil sostener que existen medidas relativas a su aplicación que son urgentes seis años después, sin ignorar que el Tribunal Constitucional ha mantenido que la valoración de la extraordinaria y urgente necesidad puede ser independiente de su imprevisibilidad e, incluso, de que tenga su origen en la previa inactividad del propio Gobierno (SS 11/2002 FJ 6, 1/2012 FJ 6 y 39/2013 FJ 8), en ambas sentencias existe a juicio del Tribunal un déficit normativo que provoca la necesidad de una regulación urgente, sin embargo, cuando la regulación se inserta en un proceso continuado e iniciado varios años antes, el Tribunal Constitucional ha declarado la nulidad por no reunir los requisitos de "extraordinaria y urgente necesidad", como ocurre con el artículo 1 del Real Decreto-Ley 4/2000, de 23 de junio (sentencia 137/2011, FJ $7^{\circ}$ ). Tampoco parece fácil establecer un nexo causal entre la situación de "grave crisis económica" y la medida adoptada y, mucho menos, justificar como la misma puede contribuir a paliar la situación coyuntural o debiéramos decir ¿estructural? 
El artículo segundo establece, la adopción de medidas cautelares urgentes en el ámbito del litoral, este precepto ofrece más dudas, puesto que se articula como una derivada de la regulación del nuevo PPCLA los razonamientos expuestos respecto del mismo deben ser aplicados a ésta última. Ahora bien, es cierto que se trata de una medida concreta, de eficacia inmediata con la que se dispensa al litoral de una protección adicional no prevista en la LOTA en base a lo cual podría justificarse la urgencia de la misma, por otro lado, sobre ella insiste la exposición de motivos al afirmar que "la tramitación como Decreto Ley se justifica por la necesidad de suspender de forma inmediata y urgente durante la elaboración del PPCLA la tramitación de los planes de sectorización y de los planes parciales en suelo urbanizable ubicados en el ámbito del Plan". Por tanto, nos inclinamos a pensar que en este punto el Decreto-Ley cumple los presupuestos habilitantes establecidos en el EAA.

La cuarta medida, contenida en el artículo $3^{\circ}$, supone la regulación de los plazos en que el planeamiento municipal debe adaptarse al POTA, entendemos que tampoco en este caso puede predicarse la urgencia por cuanto: a) han transcurrido seis años desde la aprobación del Plan Andaluz por lo que mal puede predicarse ahora urgencia alguna y, mucho menos, imprevisibilidad; b) no se establece disposición alguna de inmediata entrada en vigor, al contrario, como pondremos de manifiesto en su momento, en los casos extremos, la revisión de los planes municipales se puede demorar hasta seis años, sin tener en cuenta la demora adicional que supone su elaboración y tramitación; c) es una medida de la que no se puede predicar, en absoluto, su carácter extraordinario, pues como se razonará en su momento, innova poco el ordenamiento jurídico existente, hasta el punto de que nos atreveríamos a afirmar que se trata de una norma con un contenido jurídico irrelevante.

Por último, las Disposiciones Finales una a ocho modifican, unificando, los plazos establecidos por las distintas leyes sectoriales de la CAA para que las Administraciones sectoriales emitan informe en relación a los instrumentos de planeamiento urbanístico, se trata de una medida que agilizará, o cuando menos eso pretende, la tramitación del planeamiento municipal, en tal sentido, es una medida concreta, y puede repercutir favorablemente en el desarrollo de actividades económicas, por lo que pudiera incidir favorablemente en la "grave crisis económica", de modo que parece admisible la adopción del DecretoLey para la misma.

Por todo ello y, dadas las dudas que ofrecen las razones de urgencia esgrimidas por el Gobierno, sería deseable su tramitación como Proyecto de Ley, evitando así el vacío legal que se producirá ante un hipotético, o no tan hipo- 
tético ${ }^{19}$, recurso contra el Decreto Ley sí, una vez aprobado el PPCLA, aquél fuese anulado dejando a éste sin la cobertura legal necesaria, más cuando el Plan, probablemente, incidirá sobre derechos constitucionales como el de propiedad o libre empresa. De tramitarse como Proyecto de Ley se habría conseguido uno de los efectos principales queridos por la norma: congelar el planeamiento urbanístico que afecte al litoral y, se dotaría de mayor seguridad jurídica al nuevo Plan de Protección del Corredor Litoral de Andalucía con una ley tramitada en sede parlamentaria.

\section{LA PROTEGGIÓN DEL LITORAL}

El Decreto-Ley 5/2012 cierra, por ahora, el circulo de la protección del litoral de Andalucía que se inició hace poco menos de veintiocho años con la aprobación del Decreto 76/1985, de 3 de abril, promulgado con la única finalidad de regular el contenido y procedimiento de aprobación de las Directrices Regionales del Litoral de Andalucía.

Durante estos años, el planeamiento territorial no ha sido capaz de limitar las tendencias expansivas hacía la ocupación del litoral de determinados planeamientos municipales así, por señalar sólo alguno de los casos que han tenido mayor incidencia mediática, pueden citarse: El Algarrobico, Las Aletas o Valdevaqueros. Es más, podría afirmarse que, incluso en algunos casos se han alimentado estas tendencias, como ocurre con el recientemente anulado artículo 65 del POT de la Costa del Sol que, autorizaba en zonas que con carácter general eran calificadas como SNU de especial protección, la realización de actuaciones singulares de excelencia turística.

Ello ha ocurrido a pesar de disponer desde el año 1985 de un diagnostico correcto tanto en cuanto a la sensibilidad del espacio litoral como a los peligros que se ciernen sobre él e incluso al interés regional o supralocal de su defensa y protección, véase en tal sentido la exposición de motivos del Decreto 76/1985:

"Sobre este medio se desarrolla un elevado grado de ocupación, con multiplicidad de usos y actividades -terrestres y marítimas- que generan no sólo una alta conflictividad entre sus ocupantes y usuarios, sino tam-

\footnotetext{
${ }^{19}$ El Grupo Popular en el Parlamento de Andalucía anunció en el debate para la convalidación del Decreto-Ley la adopción de medidas "políticas y legales" contra el Decreto-Ley.
} 
bién la acumulación de riesgos e impactos que se traducen en un ritmo de deterioro y degradación altamente preocupante. En la medida en que el litoral y medio marino constituyen una importante reserva económica y ambiental que precisa de una cuidadosa y eficaz gestión para asegurar la preservación y renovación de sus recursos, y en la medida también en que la mayoría de las actividades sobre ellos desarrolladas constituyen manifestaciones de los procesos productivos asociados al desarrollo de la economía regional, es necesario que cada una de estos usos y actividades se desenvuelvan en condiciones óptimas, logrando el máximo de compatibilidad entre ellos, respetando el ecosistema en que se desenvuelven".

\section{Las Directrices Regionales de Ordenación del Litoral de Andalucía.}

Las Directrices Regionales aprobadas por Decreto 118/1990, de 17 de abril es la primera norma en nuestro Estado que de una forma global aborda la protección del litoral de una Comunidad Autónoma ${ }^{20}$.

La Directrices suponen un esfuerzo por favorecer un desarrollo sostenible del litoral andaluz. Con esta finalidad asignan al planeamiento urbanístico la obligación ${ }^{21}$ de proteger los espacios naturales y los ecosistemas necesarios para el mantenimiento del equilibrio ecológico, y para, evitar la formación de nuevos núcleos de carácter exclusivamente turístico o residencial (separados de la ciudad existente) ${ }^{22}$. Orientando las actividades hoteleras y residenciales hacia los suelos consolidados, garantizando en cualquier caso su integración con la estructura "general y orgánica del territorio". Entre sus directrices merece destacarse en este momento, las de detener los procesos que uniformicen la ordenación urbanística del litoral, evitar el trazado costero de nuevas infraestructuras de transporte, asegurar el libre acceso a la costa, así como, favorecer la utilización del territorio litoral para usos agrícolas, ganaderos, forestales, turísticos y pesqueros, todo ello conservando el equilibrio ecológico.

20 Sobre las Directrices puede verse el temprano estudio de Ortiz Diaz, J. (1990), páginas 26 a 31 y López Menudo, F. (1990), páginas 173 a 208.

21 Sobre el carácter normativo de las Directrices puede verse los autores citados en nota anterior.

${ }^{22}$ Es reseñable cómo desde el planeamiento municipal se ha incumplido la referida directriz, que se repetirá tiempo después en el POTA, y se han creado importantes núcleos turísticos separados del núcleo urbano a cuyo término municipal pertenecen. Así, a título de ejemplo, pueden citarse los núcleos de Costa Ballena en Cadiz o Islantilla, Isla Canela o Puente Esuri en Huelva. 
Las Directrices definen en los artículos 6 a 12, ambos inclusive, unas líneas de actuación y coordinación administrativa que se anticipan a las recogidas años después en los documentos europeos relativos a la política marítima integrada de la UE. De este modo, afirman que: "El espacio litoral está formado por dos sistemas naturales indisolublemente relacionados, mar y tierra. La ordenación y gestión de este espacio deberá desarrollarse de forma global e integrada" 23 , por lo que se postula una actuación concertada y coordinada de las Administraciones públicas ${ }^{24}$.

El referido planeamiento territorial identifica en el artículo $3^{\circ}$ ocho unidades territoriales: 1) sierras litorales y prelitorales; 2) acantilados; 3) dunas y arenales costeras; 4) ramblas; 5) lagunas litorales; 6) playas; 7) estuarios y marismas; y 8) provincia nerítica y plataforma continental ${ }^{25}$.

De las unidades territoriales referidas, vamos a detenernos exclusivamente en las playas por no ser las Directrices el objeto de nuestro estudio, por ser la única que se repite en todo el litoral y, por su extraordinaria sensibilidad a cualquier actuación en las mismas. Las playas se definen como "las acumulaciones de sedimentos marinos unidos a la costa y que conforman la película transitoria de detritos de roca que se acumulan a lo largo y sobre una terraza de erosión de ola. La composición de sus materiales varía desde cantos muy gruesos hasta arena fina". Definición que en lo esencial coincide con las previsiones del artículo 3.1.b) LC, cuyas disposiciones prevalecerán en todo caso.

Las directrices para esta unidad territorial son las de mantener libre de toda infraestructura la zona intermareal, conservar el carácter de espacio natural de la playa, dunas y arenales y mantener libre de toda ocupación la ribera del mar. El planeamiento urbanístico identificará en aquellas zonas donde sea posible una zona de influencia superior a los 500 metros $^{26}$; por otro lado, se impone a los planes generales la obligación de establecer normas relativas a la altura, localización y orientación de las construcciones de manera que no se pro-

23 Obsérvese como el sentido de dicha previsión coincide en lo esencial con la contenida en la Recomendación GIZC: "la protección del medio ambiente costero, formulado en términos de ecosistemas y capaz de preservar la integridad y funcionamiento de los mismos, así como la gestión sostenible de los recursos naturales de los componentes tanto marinos como terrestres de las zonas costeras".

24 También destaca este aspecto de las Directrices Sanz Larruga, F.J. (2010), página 1437.

${ }^{25}$ La identificación de las referidas unidades territoriales supone un reconocimiento y valoración de las características fisiográficas del litoral, como afirma Acosta Bono, G. (1999), página 116.

${ }^{26}$ Es sabido, que la extensión de la zona de influencia prevista en la Ley de Costas tiene el carácter de mínima (artículo 30.1). 
duzcan graves alteraciones en el régimen de brisas, lo que supone la ampliación del objeto del artículo 30 LC al ordenar la edificación teniendo en cuenta el régimen de brisas para evitar alteraciones en el mismo y no sólo evitar la formación de pantallas (artículo 30.1.b).

El fracaso o si se prefiere la poca incidencia real de las Directrices, a pesar de la valoración positiva que merecieron y merecen, tiene a mi juicio varias causas: en primer lugar su nulo valor normativo por causa de su no publicación (como es sabido sólo se publicó el Decreto de aprobación y no su contenido normativo, ni los planos que la acompañaban) lo que las hizo jurídicamente ineficaces ${ }^{27}$; en segundo lugar, por su propio carácter de avance del planeamiento por lo que su eficacia se encomendaba al planeamiento municipal; y por último, al abandono por la Administración autonómica de las mismas y confiar la protección del litoral a los planes territoriales diseñados por la LOTA y, en especial, a los planes subregionales.

\section{El POTA y los POT de ámbito subregional.}

Encomendar la protección del litoral al POTA y los POT supone un giro en la línea emprendida por las Directrices Regionales, por cuanto el POTA se limita a fijar un marco ${ }^{28}$, no siempre respetado por los POT, como veremos, por lo que en la práctica ésta se encarga a quince planes de carácter subregional aprobados entre los años 2002 y 2012, uno de cuyos cometidos es la protección del litoral y, no el más importante, si atendemos a los objetivos del Gobierno andaluz explicitados en los Decretos de formulación.

El POTA comienza por afirmar que este dominio es el espacio más dinámico, tanto desde el punto de vista demográfico como territorial y económico. Identifica las tendencias actuales hacía una progresiva transformación del territorio costero y un aumento de la densidad de ocupación urbana y turística, junto con un aumento en la presión sobre los recursos naturales. Y afirma que, "la evolución económica del conjunto de la región vendrá determinada

${ }^{27}$ Ello dió lugar a diversas denuncias del Defensor del Pueblo, véase en tal sentido el Informe Especial del Defensor del Pueblo de Andalucía de diciembre de 2009, donde se expone el desconocimiento de las mismas por parte de muchos Ayuntamientos y su inaplicación por las Comisiones Provinciales de Ordenación del Territorio y Urbanismo (páginas 37 y 38), y se recomienda que se proceda a la urgente publicación de su texto integro.Y, también el informe sobre "La ordenación y protección del espacio litoral andaluz" de octubre de 1995.

${ }^{28}$ Como afirmará tempranamente López Menudo, F. (1990), página 177, “un marco común en el que encajan todas las piezas de la planificación sectorial y proporciona fundamento y soporte a los instrumentos de planeamiento de menor ámbito". 
en el futuro, en gran medida, por la capacidad de las zonas costeras para continuar impulsando la actividad económica y la modernización del sistema productivo" 29 .

Partiendo de la situación descrita y las tendencias que analiza, el POTA delega las medidas correctoras en los planes subregionales que se formulen, si bien anticipa algunos criterios de ordenación que tienen carácter normativo $^{30}$ : a) dar prioridad a los crecimientos urbanos basados en la reordenación y recualificación de zonas de los cascos urbanos consolidados ${ }^{31}$; b) respetar la protección integral de los ecosistemas litorales (acantilados, dunas, arrecifes, zonas húmedas), así como evitar la formación de continuos urbanos en el frente costero $^{32}$; c) elaborar planes de recualificación turística que incrementen la calidad de la oferta; d) en los ámbitos menos consolidados del desarrollo turístico, realizar planes de Promoción Turística; e) en los ámbitos consolidados de agricultura intensiva, establecer criterios de gestión del agua, para la supresión a largo plazo de productos químicos en la agricultura, definición de requerimientos especiales para la ordenación urbanística y de dotaciones y servicios.

${ }^{29}$ Las principales tendencias que se observan en el dominio litoral son: a ) La concentración de un potente sistema urbano compuesto por cinco de los Centros Regionales y varias potentes Redes de Ciudades Medias, con unos fuertes ritmos de crecimiento de los usos urbanos e infraestructuras, caracterizado por unos procesos de urbanización escasamente ordenados y que tiende a una ocupación intensiva de la totalidad de espacio rural y natural costero; b) La inadecuación entre el ritmo de crecimiento y el de creación de nuevas dotaciones del sistema de transporte; c) El intenso proceso de crecimiento de las actividades turísticas basadas en el aprovechamiento de las condiciones naturales costeras, que ha consolidado un sector económico estratégico para Andalucía, cuya recualificación constituye un requisito esencial para su sostenibilidad económica y para la sostenibilidad ecológica del litoral a largo plazo; d) El igualmente intenso ritmo de crecimiento de las nuevas agriculturas, cuya sostenibilidad económica se ve directamente comprometida por factores ambientales y ecológicos tales como la disponibilidad de agua y la contaminación de acuíferos; e) El resultado de conjunto es que los recursos naturales y sus condiciones ambientales se ven sometidos a unos niveles de presión muy elevados, apuntando las tendencias actuales al incremento de dichos niveles en el futuro.

${ }^{30}$ Recuérdese que conforme al artículo 21 LOTA, las determinaciones de carácter normativo de los planes son directamente aplicables a las Administraciones Públicas y a los particulares.

31 Acosta Bono, G. (1999), página 122, expone lo complejo que resulta la reconversión de estos espacios. A su vez, Arana García, E. y Torres López, M.A. (2009), página 332, puntualizan, que la dificultad se acrecienta al tratarse de una ordenación tradicional que contempla el litoral exclusivamente desde el punto de vista de los desarrollos urbanos.

${ }^{32}$ El POTA incide y potencialmente amplia los condicionantes a los usos edificatorios en la zona de influencia de la LC: no se trata sólo de evitar la formación de pantallas arquitectónicas, sino en general de evitar los continuos urbanos en el frente costero, lo que supone, a mi juicio, impedir la ocupación lineal del litoral con usos urbanos. 
En consecuencia, podemos afirmar que, para el POTA la sostenibilidad del litoral se fundamenta en mantener el modelo de ciudad mediterránea con crecimientos contiguos al suelo urbano existente, garantizar protección y conservación de los ecosistemas litorales y, el fomento de la economía a través del desarrollo turístico y la agricultura intensiva.

A partir de estos postulados los POT debieron ordenar el litoral, sin embargo, estos se han caracterizado por: a) algunos de ellos, en concreto seis $^{33}$, se aprobaron con anterioridad al POTA sin que hasta la fecha sus determinaciones hayan sido adaptadas a aquel plan, a pesar de que, como dijimos, alguna de ellas son contradictorias con el planeamiento superior; b) estos planes de ámbito subregional han gozado de un alto grado de autonomía en su elaboración hasta el punto que en algún momento resulta difícil encontrar la existencia de una dirección común que los homologue, afirmación que puede matizarse respecto de los planes aprobados a partir del año 2009 (fundamentalmente en relación con el corredor litoral), sin que esta falta de respuestas unitarias responda siempre a diferencias territoriales, así resulta llamativo, que no se mantenga un criterio común a la hora de ordenar o no el espacio marino; c) en los POT de ámbito subregional han primado más el desarrollo económico, fundamentalmente turístico y residencial, que la protección del litoral ${ }^{34}$, así han descuidado elementos territoriales de gran importancia para el litoral como las marismas, delegando su ordenación al planeamiento ambiental, con la salvedad del POT de la Bahía de Cádiz o, las playas, cuya exigua regulación remite a unos planes de playa inexistentes, sin posicionarse sobre algunas cuestiones que han ocupado un lugar de cierta relevancia en la agenda política, como la ubicación de los llamados "chiringuitos" o la celebración de determinados eventos en las mismas, hasta el punto de existir regulaciones más exhaustivas sobre las playas en los planes de la Consejería de Turismo ${ }^{35}$.

33 POT del Poniente de Almería, aprobado por Decreto 222/2002; POT de Doñana, aprobado por Decreto 341/2003; POT de la Bahía de Cádiz, aprobado por Decreto 462/2004; POT de la Costa Occidental de Huelva, aprobado por Decreto 130/2006; POT de la Costa del Sol de Málaga, aprobado por Decreto 142/2006; POT de la Costa del Sol Oriental de la Provincia de Málaga, aprobado por Decreto $147 / 2006$.

${ }^{34}$ Característica, de alguna forma reconocida por la Administración andaluza al establecer en la exposición de motivos del Acuerdo de 29 de enero de 2013 por el que se formula el PPCLA: "Los planes de ordenación del territorio de ámbito subregional han establecido criterios al planeamiento urbanístico para la ordenación de los municipios costeros, pero se precisa de un instrumento específico de protección que aborde el corredor litoral en su integridad a escala adecuada, a fin de servir de orientación a los planes municipales en su ordenación detallada".

35 Desde la Consejería de Turismo, Comercio y Deporte se elaboró en julio de 2005 un plan de playas denominado "playas divertidas de Andalucía" que puede consultarse en http://www.juntadeandalu- 
De los POT de ámbito subregional, además de lo dicho, parece conveniente destacar dos elementos por su interés para el estudio del Decreto-Ley 5/2012, por un lado la definición más o menos homogénea, a partir del año 2009, del "corredor litoral" cuyo ámbito incluye: el dominio público marítimo terrestre, la servidumbre de protección y los suelos clasificados como no urbanizables y urbanizables no ordenados en una banda de al menos 200 metros medidos tierra adentro desde el límite interior de la ribera del mar, este ámbito se excluye de su transformación urbanística fomentando en ellos las actividades de ocio, recreativas y deportivas.

El segundo elemento a destacar es como a través de las excepciones establecidas en los mismos han dejada en letra muerta la norma del POTA que impone un crecimiento continuo al núcleo urbano, así el POT de la Costa del Sol Oriental mantiene la regla anterior fundamentalmente para los suelos de uso residencial. En el caso de los suelos de uso vacacional ${ }^{36}$ se establece un distinto tratamiento si son colindantes ${ }^{37}$ o si no lo son, pero no se limitan los crecimientos discontinuos con el suelo urbano cuando se trata de usos vacacionales; el POT del Litoral Occidental de Huelva permite la consolidación de los suelos discontinuos existentes en el planeamiento anterior al POT, y aun cuando no hubieran iniciado su desarrollo siempre que se trate de suelo de uso turístico o, finalmente, el POT de la Bahía de Cádiz tiene en cuenta la necesidad de valorar la incidencia que produzcan en los ecosistemas afectados y en los recursos naturales y paisajísticos del entorno, la valoración de la capacidad de las infraestructuras existentes para absorber los nuevos crecimientos ${ }^{38}$. Ello ha producido que pese a las prohibiciones y limitaciones existentes desde 1991 en las Directrices Regionales, en nuestra Comunidad han proliferado los crecimientos discontinuos con el núcleo urbano existente, provocando, en no pocas ocasiones, y desde luego en momentos de crisis como el actual, espacios difíciles de proveer de los más elementales servicios urbanos y, en consecuencia, con un costoso mantenimiento tanto para los Ayuntamientos como para los propietarios, formando un espacio de exclusividad.

cia.es/turismocomercioydeporte/opencms/planificacion/turismo/plan_0004.html. Última consulta $12 / 12 / 2012$.

${ }^{36}$ Éste parece ser un uso más amplio que el turístico, común a la mayoría de los planes, que debe incorporar no sólo el uso turístico sino también el de segunda residencia.

${ }^{37}$ De ser colindantes deberán garantizar la continuidad urbana, estableciendo para ellos una edificabilidad no residencial del cuarenta por ciento de la edificabilidad total y, como recomendación, que la edificabilidad bruta no sea superior a $0,3 \mathrm{~m}^{2 \mathrm{t}} / \mathrm{m}^{3 \mathrm{~s}}$.

${ }^{38}$ Este criterio debería ser de general aplicación sea donde fuere que se produzca el nuevo crecimiento, pues para todos ellos es preciso que existan infraestructuras, sobre todo de agua y eléctricas, suficientes. 
Probablemente el POTA es consciente de este relativo fracaso de la política de protección del litoral de nuestra Comunidad, por lo que propugna un "programa regional de ordenación del litoral". Este programa debiera abordar, como afirma el POTA, las políticas regionales en materia de ordenación del territorio y medio ambiente, las políticas turística, fundamentalmente los modelos de implantación turística; agrícola, especialmente en lo que se refiere a la agricultura intensiva e invernaderos; hidráulicas y forestales. De este modo, la propuesta del Plan Andaluz postulando la formulación de un nuevo programa regional de ordenación del litoral que aborde "la complejidad de los procesos de desarrollo territorial que se producen en el litoral" parece ser el antecedente inmediato del Plan de Protección del Corredor Litoral de Andalucía (PPCLA).

\section{El Plan de Protección del Corredor Litoral de Andalucía.}

Como se dijo, Andalucía vuelve a sus orígenes encomendando la protección, conservación y puesta en valor del litoral a un plan regional cuyo cometido será la protección del espacio que él mismo defina como litoral y, el establecimiento de las normas que garanticen un tratamiento homogéneo del mismo.

Con tal objeto, el artículo primero del Decreto-Ley 5/2012 modifica el artículo $5^{\circ}$ y 22.1 de la LOTA y añade a la misma un nuevo título, el séptimo. Estas modificaciones tienen como finalidad incorporar a la ordenación del territorio de Andalucía un nuevo plan territorial denominado Plan de Protección del Corredor Litoral de Andalucía (PPCLA), con el que se pretende, por un lado, ordenar el litoral salvando las omisiones de los POT y, en segundo lugar, que dicha protección sea homogénea, común a en todo espacio costero andaluz, pretensiones ambas que merecen ser alabadas, aún cuando, a nuestro juicio, no era precisa la reforma acometida para que se pudiera elaborar un plan de estas características.

Un plan como el propuesto tendría dos coberturas posibles: a) como plan territorial de ámbito subregional cuyo territorio abarcase la totalidad de los términos municipales con litoral (artículo 14 LOTA) y, b) un plan de carácter intermunicipal amparado en una interpretación laxa del artículo 11 de la LOUA, con la ventaja adicional, en este caso, de que estos planes pueden clasificar suelo, lo que permite que sus efectos sobre el litoral tengan una mayor inmediatez. Posibilidad, esta última, que tampoco se cierra por la elaboración y aprobación del PPCLA.

El PPCLA, en consecuencia, se incorpora a la ordenación del territorio como un nuevo tipo de plan territorial caracterizado por tener un ámbito infe- 
rior al de la Comunidad Autónoma, pues abarca la totalidad de los municipios litorales de nuestra CA sin ordenar, necesariamente, la totalidad de sus términos, es decir, un plan de ordenación cuyo ámbito se limite al litoral en sentido estricto como ocurre en otras CCAA, fundamentalmente responden a este modelo los Plan Director Urbanístico del Sistema Costero (PDUSC) de la Comunidad Autónoma de Cataluña y, en menor medida, el POLA asturiano, si bien estos son planes urbanístico y no territoriales.

Este modelo con un plan único que ordena la totalidad del litoral, aparentemente, ha funcionado bien en Comunidades como Cataluña y el Principado de Asturias, sin embargo, en nuestra CA puede tener algunas dificultades derivadas del tamaño del litoral andaluz, muy superior a las CCAA citadas, casi mil kilómetros de costa, frente a los 547 kilómetros del litoral catalán y 200 kilómetros del asturiano. Por ello, a nuestro juicio, hubiese sido conveniente crear, junto al PPCLA, la figura de planes territoriales litorales de ámbito inferior y sometidos jerárquicamente a aquél que ordenasen, por ejemplo, unidades fisiográficas de características similares. No obstante y, a falta de estos planes de ámbito inferior, se pueden utilizar con la misma finalidad los POT, ahora ya, con unos objetivos y determinaciones claros en cuanto a la protección del litoral se refiere, en cuanto éstos vendrían impuestos desde el PPCLA o, lo que a mi juicio puede ser más interesante, los planes intermunicipales, lo que permitiría clasificar suelo directamente, sin necesidad de esperar al planeamiento municipal.

En detrimento de esta última opción pudiera afirmarse que con ella se corre el riesgo de invadir competencias municipales, riesgo sin duda cierto, pero que no se obvia por ordenar el litoral con un plan territorial, ni aquel es mayor por ordenarlo con un plan urbanístico. Para garantizar la autonomía municipal es preciso, en primer lugar, dar participación a los municipios afectados en la elaboración de estos planes y, en segundo lugar, limitar la ordenación realizada en los mismos a los elementos supramunicipales sin descender a prescripciones de vocación municipal, en tal sentido puede verse una ya copiosa jurisprudencia del TS, entre las que se pueden citar las sentencias de 20/12/2012, recursos núm. 2433/2009; 3424/2009 y 6119/2009, así como, la doctrina de los TSJ, así las sentencias de Cataluña de 13/01/2009 (recurso 396/2006); 13/03/2009 (recurso 321/2005); 27/09/2009 (recurso 510/2006); 22/04/2010 (recurso 662/2006); 27/07/2011 (recurso 312/2007). Y, Asturias de 27/10/2008 (recurso 1593/2005).

La posición que ocupa el nuevo plan en el conjunto del planeamiento territorial andaluz no está del todo clara en el El Decreto Ley. Éste especifica la 
prevalencia de las disposiciones del PPCLA sobre los POT (artículo 42.2) pero, incomprensiblemente, no hace lo mismo respecto de los PIOT y del planeamiento municipal, si bien a ambos se refiere la letra f) del artículo 43 al establecer:

El PPCLA contendrá las determinaciones de los POT, de los PIOT y del planeamiento urbanístico que deban ser objeto de adaptación, justificando las alteraciones propuestas para los mismos.

Lo anterior nos situaría ante la siguiente lectura, el Plan del Litoral es vinculante para los POT, sin embargo para los PIOT y planes municipales sólo lo será o, si se prefiere, sólo deberán adaptar sus determinaciones al PPCLA, cuando expresamente lo diga y justifique el plan del Litoral.

Sin embargo, una interpretación de este tipo, a mi juicio, no tendría en cuenta que los POT, a su vez, son vinculantes para los PIOT y para el planeamiento municipal, por lo que aprobado el PPCLA, con las matizaciones que haremos a continuación, aquellas determinaciones que sean contrarias a los POT son sustituidas por las del PPCLA, pues no otra cosa significa que son vinculantes. Pues bien, incorporadas a los POT y dado que éstos son vinculantes para el planeamiento municipal, éste debe adaptarse a aquél (artículos 23.1 y 4 LOTA Y 35 LOUA). Ésta es, también, la interpretación del Gobierno andaluz que en la exposición de motivos del Acuerdo de formulación del PPCLA (Acuerdo de 29 de enero de 2013) afirma que será vinculante para los PIOT y planeamiento municipal. Obviamente esta vinculación se refiere, exclusivamente, a aquellas disposiciones que según el PPCLA tengan carácter de norma, las que tengan carácter de directriz obligarán a los POT a su modificación ajustándose a los fines de la misma (artículo 21 LOTA).

Más claro resulta la dependencia del nuevo plan del POTA, cuyas determinaciones habrá de respetar en cualquier caso (artículo 22.1 nueva redacción), si bien, que con los mismos límites que acabamos de referir establecidos en el artículo 21 LOTA.

A. Objetivo, ámbito y contenido.

\section{a). Objetivo.}

El Plan tiene por objeto, como establece la exposición de motivos del Decreto-Ley, abordar la ordenación del corredor litoral de una forma unitaria e 
integradora para garantizar la protección, conservación y puesta en valor de la riqueza ambiental y paisajística existentes en el litoral andaluz, manteniendo, continúa la exposición de motivos, libre de urbanización "los espacios no edificados que no sean necesarios para la normal expansión de nuestros pueblos y ciudades y, encauzando de este modo los planes municipales para garantizar un desarrollo sostenible adecuado a la capacidad de acogida del territorio ${ }^{39}$.

Parece evidente, pues, que el PPCLA debe adoptar una ordenación unitaria e integradora siguiendo las prescripciones sobre Gestión Integrada de Zonas Costeras de la Unión Europea, entendiendo por tal, como afirma la Unes$\mathrm{Co}^{40}$, aquel "proceso dinámico que reúne gobiernos y sociedades, ciencias y administradores, intereses públicos y privados en pro de la protección y del desarrollo de sistemas y recursos costeros. Este proceso intenta optimizar las alternativas a largo plazo privilegiando los recursos y su uso racional y razonable". La gestión de zonas costeras es, por tanto, una gestión integrada en el tiempo y en el espacio y es intrínsecamente pluridisciplinar. Se trata, como abunda Sanz Larruga ${ }^{41}$, de abandonar los métodos tradicionales de planificación y gestión caracterizados por una visión sectorial para adoptar un enfoque ecosistémico que tenga en cuenta la interdependencia y disparidad de los sistemas naturales y las actividades humanas con incidencia en las zonas costeras. Como ya hemos mantenido en otras ocasiones ${ }^{42}$, y afirman de modo concluyente las Directrices Regionales, "el espacio litoral está formado por dos sistemas naturales indisolublemente relacionados, mar y tierra. La ordenación y gestión de este espacio deberá desarrollarse de forma global e integrada".

Por enfoque ecosistémico se entiende la estrategia para la gestión integrada de tierras, extensiones de aguas y recursos vivos por las que se promueve la

\footnotetext{
${ }^{39}$ Exposición de motivos I.

Por normal expansión de nuestras ciudades ha de entenderse no sólo los crecimientos demográficos, sino también las necesidades derivadas de actividades económicas, como el turismo, por lo que tal expresión aporta poco a la interpretación de los objetivos del nuevo Plan, si no fuese porque a continuación se añade que con el mismo se encauzará el desarrollo sostenible adecuado a la capacidad de acogida del territorio. Por tanto la clave de bóveda para su adecuado entendimiento es la capacidad de acogida del territorio, que se convierte de esta forma en un límite que no debe superarse por el planeamiento litoral al diseñar los nuevos crecimientos que, estos sí, deberán estar justificados en razones demográficas o económicas.

${ }^{40}$ Definición adoptada de CINCIN-SAIN (1998) en Instrumentos y personas para una gestión integrada de las zonas costeras. Unesco 2001. página 8. Puede consultarse en:

http://unesdoc.unesco.org/images/0012/001245/124596s.pdf. Última consulta Diciembre 2012.

${ }^{41}$ Sanz Larruga, F.J. (2010), página 1302.

42 Véase Zamorano Wisnes, J. (2013), páginas 64 a 67.
} 
conservación y utilización sostenible de modo equitativo. Este enfoque debe aspirar a la conservación de la estructura y al funcionamiento de los ecosistemas para mantener los servicios que provee ${ }^{43}$. Si se trabaja en sintonía con ellos, y no contra ellos, respetando su capacidad de carga, se consigue que las actividades sean menos perjudiciales para el ambiente y es posible aumentar las posibilidades de éxito con vistas al futuro, al hacer las actuaciones que se emprendan más sostenibles.

\section{b). Ámbito.}

En cuanto al ámbito del futuro PPCLA, la Ley adopta un modelo similar al seguido en otras CCAA incluyendo dentro del mismo los terrenos que se encuentren en la zona de influencia de la LC, si bien deja abierta la posibilidad de incorporar otras zonas "necesarias para alcanzar los objetivos de protección y accesibilidad del sistema costero", evitando la consolidación de nuevas barreras urbanas entre los espacios interiores y el sistema costero y favorecer la biodiversidad a través de la continuidad de los espacios del interior con los del litoral, añade entre los objetivos generales del nuevo plan el Acuerdo de formulación.

Ello parece implicar ad initio una renuncia a ordenar de forma unitaria, integrada, los espacios terrestres y marítimos ${ }^{44}$, lo cual, si bien ha sido una cons-

43 Para profundizar en el estudio del método basado en los ecosistemas véase Jaquenod De Zsógón, S. (2008), páginas 245 a 250. que reproduce los principios para la aplicación del método del ecosistema, elaborados por la UICN (Unión Internacional para la Conservación de la Naturaleza) para apoyar la aplicación de la Convención sobre la diversidad biológica: 1. Los objetivos de manejo del suelo, agua y recursos son asunto de la preferencia de la sociedad. 2. El manejo debe descentralizarse hasta el nivel apropiado más bajo. 3. Los administradores de ecosistemas deben considerar los efectos de sus actividades sobre ecosistemas adyacentes o sobre otros ecosistemas. 4. Cualquier programa de manejo de ecosistema debe: a) reducir las distorsiones del mercado que afecten negativamente a la diversidad biológica; b) alinear incentivos para promover la conservación y el uso sostenible de la biodiversidad; c) internalizar los costos y beneficios de un ecosistema dado, en la medida de lo posible. 5. Una meta prioritaria del método del ecosistema debe ser la conservación de la estructura y el funcionamiento de los ecosistemas, para mantener los servicios que provee. 6. Los ecosistemas deben manejarse de acuerdo a sus límites de funcionamiento. 7. El método del ecosistema debe abordarse de acuerdo a las escalas espaciales y temporales apropiadas. 8. Reconociendo las escalas temporales variables y de los efectos de laguna que caracterizan a los procesos de los ecosistemas, los objetivos de manejo de ecosistemas deben fijarse a largo plazo. 9. El manejo debe reconocer que el cambio es inevitable. 10. El método de ecosistema debe procurar un balance e integración apropiada entre la conservación y el uso de la diversidad biológica. 11. El método del ecosistema debe considerar todas las formas de información relevantes, incluyendo conocimiento científico, local y el indígena, así como innovaciones y prácticas. 12. El método del ecosistema debe involucrar a todos los sectores relevantes de la sociedad y disciplinas científicas También puede verse Parejo Navajas, T. (2011), páginas 113 y 114.

${ }^{44}$ En relación a la competencia de las CCAA para ordenar el espacio marítimo ha tenido ocasión de pronunciarse en diversas sentencias el TC, entre ellas cabe destacar las 38/2002; 31/2010 y 162/2012, en 
tante en el planeamiento territorial de nuestro Estado, con la excepción Euskadi, a nuestro juicio, no debiera mantenerse en nuestra CA, sino que, al amparo de la competencia asumida en el Estatuto de Autonomía en materia de ordenación del litoral (artículo 56.6) ${ }^{45}$, debiera intentarse un Plan que ordenase de forma integrada tanto los espacios terrestres como marítimos, así como los criterios para la ocupación del dominio público marítimo terrestre, incluidas las obras fijas en el mar, abordando desde el mismo, cuestiones de notoria importancia para el litoral y su desarrollo como, la ubicación en el mar de instrumentos generadores de energía, plataformas para prospecciones de gas o petróleo, pues de ubicarse éstas en zonas próximas a la costa pueden redundar negativamente en su desarrollo turístico, tratándose de cuestiones que, a nuestro juicio, no puede o no debe omitir el futuro Plan del Litoral.

También se anuncia la exclusión de las "zonas contiguas" a los márgenes de los ríos, previsión que dada su falta de concreción habrá de estarse a lo que finalmente disponga el PPCLA ${ }^{46}$, pero que en principio parece de discutible oportunidad, por cuanto que se excluiría del Plan, no ya las márgenes de los ríos definidas en el artículo 6 TRLA ${ }^{47}$, sino los terrenos contiguos de los que desconocemos anchura, profundidad y usos, pudiendo muy bien ocurrir que los planes hidrológicos no les dispensen ninguna protección o ésta sea menor que la otorgada por el PPCLA a los "corredores" que sirvan de conexión entre el

las que se mantiene que sobre el mar territorial las CCAA ejercen competencias con carácter excepcional, como consecuencia de un reconocimiento estatutario explícito o "cuando la naturaleza de la competencia tal como resulta de la interpretación del bloque de la constitucionalidad".

Pues bien, existiendo tal reconocimiento estatutario como ocurre con el artículo 56.6 EAA, el ejecutivo andaluz debiera ejercer tal competencia que, por otro lado, resulta aconsejable en aplicación del Protocolo relativo a la Gestión Integrada de Zonas Costeras para el Mar Mediterráneo (GIZC-MED) (ratificado por España mediante Instrumento de 20/05/2010 y la Recomendación 2002/413/CE sobre Gestión Integrada de Zonas Costeras (GIZG). Sobre estas cuestiones puede verse Zamorano Wisnes, J. (en prensa), páginas 40 a 50, también Zambonino Pulito, M. (2009), página 416 y González García, J y Zambonino Pulito, M, (2010), páginas 108 a 111 y 113 a 117. Y, en relación a la GIZC, el mismo autor, el capítulo V dedicado a la GIZC.

45 Sobre la competencia del artículo 56.6 EAA puede verse Zamorano Wisnes, J. (2013), páginas 193 a 209 .

${ }^{46}$ El Consejero de Agricultura, Pesca y Medio Ambiente en su comparecencia ante el Pleno del Parlamento Andaluz en el debate previo a la convalidación del Decreto Ley 5/2012, parece referirse a las zonas contiguas como un espacio que se prolonga tierra adentro y no como un espacio paralelo a los márgenes del río, así afirma textualmente "excluyendo de este ámbito de influencia las áreas contiguas a los márgenes de los ríos, allí donde, como ocurre en el caso del Guadalquivir, las zonas de protección del dominio público llegan más allá de Sevilla”. Véase el Diario de Sesiones del Parlamento de Andalucía. Plenos (DSPA Plenos) número 23.

${ }^{47}$ Real Decreto Legislativo 1/2001, de 20 de julio. 
sistema costero y el interior territorial, creando de este modo vacíos de ordenación de dificil comprensión.

Entiendo que avanzar a través del Plan en la línea de la GIZC, como proponemos, supone la planificación del espacio mediante la incorporación de las distintas funciones públicas y actividades privadas ${ }^{48}$, entre ellas obviamente la planificación hidrológica, lo que supondría incorporar sus previsiones al nuevo Plan, en lugar de dejar fuera de su ámbito un espacio que, en principio, no forma parte del plan hidrológico. En el peor de los casos, parece más razonable incluir estos espacios en el ámbito del Plan y, de estimarse oportuno, establecer normas que hicieran prevalecer los planes hidrológicos para los suelos protegidos por estos.

\section{c). Contenidos materiales.}

Por lo que respecta a los contenidos interesa destacar las previsiones de las letras c), d) y e) del nuevo artículo 43, pues en ellas concreta el legislador andaluz el nuevo modelo territorial de nuestro litoral.

En primer lugar el PPCLA, de acuerdo con lo dispuesto en la letra c), va a determinar un ámbito excluido de su futura transformación urbanística, o lo que es lo mismo un ámbito que el planeamiento municipal tendrá que clasificar como SNU, ámbito que no considero demasiado aventurado afirmar que va a coincidir con los suelos clasificados como no urbanizables y urbanizables no ordenados en una banda de al menos 500 metros medidos tierra adentro a partir del dominio público marítimo terrestre, pues esta es la distancia que se señala como ámbito mínimo en el nuevo artículo 42 LOTA y en el artículo 2.1 del Decreto-Ley; y a ella se hace referencia expresa en la exposición de moti$\operatorname{vos}^{49}$, en el artículo segundo del Acuerdo de formulación, y, por último, es la utilizada por la práctica totalidad de los planes de ordenación del litoral. aprobados a partir de $2009^{50}$. Por tanto, estarán excluidos del ámbito del PPCLA, aún cuando se encuentre en la zona de influencia de la LC, tanto los suelos urbanos, por razones obvias, como los suelos urbanizables ordenados.

\footnotetext{
${ }^{48}$ Véase en tal sentido Núñez Lozano, M.C. y Zamorano Wisnes, J. (2012), páginas 1759 y 1760,

${ }^{49}$ Este es también el sentido de la intervención del Consejero de Agricultura, Pesca y Medio Ambiente si bien en la misma matizó que tal medida afectaría a los SNU o protegidos existentes y a los suelos urbanizables no desarrollados que sean incompatibles con el modelo de crecimiento propuesto. Véase la comparecencia ante el Pleno del Parlamento citada.

${ }^{50}$ Sobre los POT de carácter subregional que ordenan el litoral andaluz puede verse Zamorano Wisnes, J (2013), capítulo séptimo.
} 
Otro de los cometidos que se asignan al futuro plan es el establecimiento de un régimen de usos "homogéneo para las distintas categorías de suelo no urbanizable", con lo que parece estarse pensando en hacer distintas subclasificaciones de ese SNU Costero, al modo de lo realizado por otros planes de ordenación del litoral, clasificación que, sin duda, estará amparada en las características naturales del suelo o su mayor sensibilidad ante cualquier actividad humana o en su menor capacidad de acogida.

En la intervención del Consejero de Agricultura, Pesca y Medio Ambiente ${ }^{51}$ se hizo referencia al posible establecimiento de condiciones para el desarrollo de los suelos urbanizables sectorizados con la finalidad de adecuarlos a los objetivos de protección establecidos en el Plan, a este grupo de determinaciones no hace referencia alguna el Acuerdo de formulación. No obstante lo cual, se podrían intentar al incluir el Plan suelos clasificados por el planeamiento municipal como suelos urbanizables sectorizados, respecto de los cuales el Plan del litoral puede plantear dos tipos de operaciones, en unos casos, imponer al planeamiento municipal su clasificación como no urbanizable, lo que no plantea mayores problemas siempre que dicha clasificación venga impuesta por razones supramunicipales y, en otros, mantener su clasificación y establecer criterios para su ordenación pormenorizada. En relación a esta segunda operación hay que tener en cuenta que la reciente jurisprudencia del Tribunal Supremo en relación con el PDUSC ha mantenido una posición crítica ${ }^{52}$.

Un último cometido asignado por la Ley al PPCLA es la delimitación de corredores, definidos como ámbitos de conexión del sistema costero con el interior territorial, una de cuyas funciones sería evitar la consolidación de nuevas barreras entre los espacios interiores y el sistema costero y favorecer la bio-

\footnotetext{
51 Véase la intervención del Consejero de Agricultura, Pesca y Medio Ambiente, citada.

52 Para ello, el Tribunal Supremo parte de la tradicional distinción contenida en la sentencia de 13/07/1990, entre las determinaciones que afectan a un interés puramente local y las que afectan a un interés supramunicipal, para a continuación distinguir entre el control a posteriori que ejerce las CCAA en la aprobación del planeamiento municipal al que es de aplicación la doctrina citada, del realizado a priori a través de las determinaciones del Plan Director Urbanístico del Sistema Costero 2 (PDUSC-2), "la Administración autonómica pueda fijar de antemano los parámetros y magnitudes a los que necesariamente habría de atenerse el planeamiento municipal". Esta segunda opción puede cercenar la autonomía local ya que el margen de apreciación y de discrecionalidad del Ayuntamiento queda bloqueado pro futuro. Este criterio se ha mantenido incluso cuando las determinaciones han sido introducidas en el Plan supramunicipal a propuesta del Ayuntamiento afectado (STS 20/12/2012, rec. 4806/2009). La jurisprudencia reseñada puede verse, además de en la sentencia citada, en las de la misma fecha, recursos 2426/2009 y 3569/2010. No obstante, el mismo Tribunal, ha matizado su doctrina en alguna otra sentencia, así ha entendido que no se vulnera la autonomía local cuando las prescripciones para la ordenación del suelo urbanizable establecidas en el PDUSC-2 tienen un carácter amplio, de generalidad, sentencia de 20/12/2012, rec. 6119/2009.
} 
diversidad garantizando la continuidad entre los espacios del interior y los suelos litorales, para identificar esta categoría de suelo el legislador andaluz parece influido por el PDUSC- ${ }^{53}$, único plan del litoral que contempla esta categoría con la denominación de "Suelo no urbanizable de costas-1", caracterizada por sus valores intrínsecos y por su capacidad para actuar como conector entre los ámbitos propios de litoral y los suelos de interior o de segunda línea. Pues bien, en el PDUSC-1 estos suelos, los corredores, son los que alcanzan el mayor nivel de protección o lo que es lo mismo, las mayores limitaciones de uso de las distintas categorías del SNU de Costas.

\section{B. Procedimiento.}

El procedimiento de tramitación y aprobación del PPCLA tiene más similitudes con el contenido en el artículo 8 LOTA que regula el procedimiento de elaboración del POTA, que con el artículo 13 de la Ley que ordena el procedimiento de aprobación de los POT de ámbito subregional, lo cual parece lógico, dado el ámbito territorial y los municipios afectados en unos y otros, por nuestra parte, vamos a limitar estos comentarios a las singularidades reguladas en el Decreto-Ley.

Lo primero que llama la atención es la desaparición de toda referencia a la "composición y funciones de la Comisión de Redacción" regulada en la LOTA tanto para el POTA como para los POT de ámbito subregional, lo que ha sido subsanado, en parte, en el Acuerdo de formulación. La Comisión de Redacción en el Decreto de formulación del POTA se constituye como un órgano con funciones de dirección y seguimiento de los trabajos de redacción, así como, el establecimiento de los criterios y estrategias y la selección de los objetivos del Plan. Estas funciones, en el Acuerdo de formulación y en relación con el PPCLA, se han visto reducidas de modo sensible, limitándose a: informar el contenido del plan y de las modificaciones que se introduzcan como consecuencia de los tramites de información pública y de audiencia (artículo $5^{\circ} .6$ del Acuerdo de formulación).

${ }^{53}$ El Plan Director Urbanístico del Sistema Costero 1 (PDUSC-1), aprobado el 25 de mayo de 2005, incluye los suelos no urbanizables (SNU) y urbanizables no delimitado (no sectorizado) que se encuentren dentro de la zona de influencia, así como, los ámbitos exteriores identificados en el plan por "su capacidad de conectar entre los ámbitos más propios del litoral y los espacios interiores, tierra adentro, o por la concurrencia de otros valores dignos de protección"; Unos meses después, en diciembre de 2005, se aprobó el Plan Director Urbanístico del Sistema Costero 2 (PDUSC-2), que incluye los suelos urbanizables delimitados (sectorizados) sin plan parcial aprobado enumerados en su artículo 4.3. que se encuentre total o parcialmente dentro de la zona de influencia. 
Su composición es asimétrica con un amplia representación de la Administración de la Junta de Andalucía, cinco representantes de los municipios afectados y un exiguo representante de la Administración del Estado .

La Disposición Adicional del Decreto Ley impone que el PPCLA se someta a información pública en un plazo "no superior a seis meses desde su formulación", se trata de una novedad que no contenía la LOTA en relación con la tramitación del POTA, ni con los POT, otra cosa será que se cumpla el plazo prescrito que supone ni más ni menos que el Plan debe estar elaborado ${ }^{54}$, cuando menos en aspectos suficientes como para someterlo a información pública, en un plazo de seis meses desde la publicación del Acuerdo por el que se decide su formulación, ello supone que el Plan debe someterse a información pública antes del 14 de agosto, lo que, desde luego, no ha sido habitual en la planificación territorial.

El plazo de información pública no podrá ser inferior a dos meses, sometiendo el Plan de forma simultánea, y por el mismo plazo, a audiencia de la Administración General del Estado, de las Diputaciones en cuyas provincias haya municipios litorales, de los Ayuntamientos de los municipios incluidos dentro del ámbito del Plan y de las restantes Administraciones y Entidades Públicas afectadas en razón de su competencia. Finalmente, y en el mismo plazo, se solicitará informe a la Comisión de Ordenación del Territorio y Urbanismo de Andalucía y a las Comisiones Provinciales de Ordenación del Territorio y Urbanismo de las provincias con municipios litorales.

Una vez concluido el periodo de información pública se redactará la memoria ambiental prevista en el artículo 39 de la Ley GICA ${ }^{55}$.

Una última novedad es la obligación de dar cuenta de la aprobación del Plan al Parlamento que, en principio, no conlleva intervención alguna por parte de éste, se trata de una medida intermedia entre la intervención del Parlamento en la aprobación del POTA y su ausencia en la aprobación de los POT de ámbito subregional.

\section{G. Medidas cautelares.}

El artículo segundo del Decreto-Ley establece una medida cautelar, consistente en paralizar los procedimientos de aprobación de los planes de sectoriza-

\footnotetext{
${ }^{54}$ Como elaboración técnica lo designa el Acuerdo de formulación.

${ }^{55}$ Ley $7 / 2007$, de 9 de julio, de gestión integrada de la calidad ambiental.
} 
ción y parciales de los municipios incluidos en el anexo I (municipios litorales cuyo plan general se aprobó antes del POTA), siempre que en el ámbito de dichos planes se incluyan terrenos pertenecientes a la zona de influencia.

La medida es, sin duda, modesta, pues a decir de la exposición de motivos, responde al objetivo de paralizar los "modelos urbanísticos" nacidos durante los años del boom económico que representan "expectativas justificadas por demandas exógenas propias de otra situación económica" que producen crecimientos urbanos no sostenibles. Ello es sin duda encomiable, ahora bien, a mi juicio una medida de estas características debiera garantizar la efectividad del futuro plan impidiendo que el desarrollo urbanístico del planeamiento municipal frustre las expectativas del PPCLA u obliguen a importantes desembolsos económicos al tener que indemnizar como consecuencia de modificaciones en la clasificación del suelo producidas en el indicado planeamiento, ex artículo 25 Texto Refundido de la Ley del Suelo $\left(\right.$ TRLS) ${ }^{56}$. Ello ocurrirá si el plan costero pretende clasificar como SNU de Costas suelos que, incluidos en la zona de influencia de la LC, al momento de la formulación del Plan estén clasificados como urbanizable sectorizado o no y, antes de su aprobación, y en desarrollo de planes generales aprobados a partir de noviembre de 2006 (es decir después del POTA), sean desarrollados mediante la aprobación del correspondiente plan parcial, asignando a dichos suelos usos tales como residencial, turístico, industrial o comercial ${ }^{57}$, lo que podría hacerse, en muchos casos, respetando las previsiones de la LC, LOUA, POTA y POT.

En coherencia con lo anterior considero que hubiese sido más oportuno suspender la tramitación de la totalidad de los planes parciales de ordenación que afectasen a la zona de influencia e, incluso, el inicio de las actuaciones de gestión del planeamiento en aquellos supuestos (son muchos en este momento $)^{58}$ en que hubiesen transcurrido los plazos previstos para su desarrollo, con lo que la efectividad del PPCLA hubiese sido sensiblemente superior.

El apartado segundo, que ha de ser interpretado en relación con los apartados primero y tercero, establece que una vez sometido a información pública el Plan costero sólo se mantendrá la suspensión a que hace referencia el

\footnotetext{
${ }^{56}$ Aprobado por Real Decreto Legislativo 2/2008, de 20 de junio.

${ }^{57}$ Por supuesto ignoro si las Direcciones Generales de Ordenación del Territorio y Urbanismo de la Junta de Andalucía han valorado los efectos que estas actuaciones pudieran provocar en el litoral.

${ }^{58} \mathrm{El}$ Consejero de Agricultura, Pesca y Medio Ambiente en su intervención en el Parlamento de Andalucía, citada, afirma que en la primera línea de costa existen más de 30 millones de metros cuadrados en sectores de suelo ordenado pendiente de ejecutar, con una capacidad para construir 40.000 viviendas.
} 
apartado primero para los sectores "afectados por las determinaciones de dicho Plan que se identifiquen expresamente en el documento". Es decir, el documento que salga a información pública sólo podrá identificar SNU o urbanizables sectorizados o no, que se encuentre en la zona de influencia y correspondan a planes municipales que fueran aprobados con anterioridad al POTA. Lo que supone que si el nuevo documento de planeamiento considera preciso proteger un suelo que se encuentre fuera de la zona de influencia, al tratarse, por ejemplo, de un "corredor" que sirva de conexión entre el sistema costero y el interior territorial o, un suelo urbanizable de un plan municipal aprobado con posterioridad al POTA habrá de hacerlo sin poder utilizar la medida de suspensión cautelar prevista en el artículo 2 del Decreto Ley, con las consecuencias indemnizatorias que de ello se derivarían, como se dijo.

El apartado tercero incide en la línea apuntada, al limitar la suspensión a un máximo de dos años, lo que coincide con el plazo establecido en la Disposición Adicional única para aprobar el PPCLA por lo que parece suficiente, aún cuando la experiencia de la planificación territorial de nuestra Comunidad ha superado ampliamente este plazo. Singular resulta la prescripción contenida en el párrafo segundo de este tercer apartado al dejar sin efecto la suspensión para aquellos planeamientos municipales que durante el periodo máximo de suspensión adapten sus determinaciones al POTA, con lo que, se abunda en que el objeto de la suspensión es fomentar la adaptación de los planes municipales al POTA y no garantizar la efectividad de las determinaciones del PPCLA.

\section{LA ADAPTACIÓN DEL PLANEAMIENTO MUNICIPAL AL POTA}

El Decreto Ley 5/2012, aborda en los artículos 1 y 3 una segunda cuestión: la relativa a la prevalencia del POTA sobre el planeamiento municipal y, consecuente la obligación de su adaptación al Plan Andaluz, mediante la innovación de los instrumentos de planeamiento municipal. Para ello, el artículo 1 modifica el artículo 22.1 de la LOTA aclarando que el Plan Andaluz es también vinculante para el planeamiento urbanístico general. El artículo $3^{\circ}$, a su vez, establece plazos para la adaptación del planeamiento municipal al POTA, esta disposición se justifica en la exposición de motivos por la necesidad de evitar desequilibrios territoriales entre los planes elaborados a partir del 2006 y los aprobados con anterioridad, "que responden en muchos casos a modelos de crecimiento no sostenibles, alejados del actual contexto socioeconómico y de los criterios y limitaciones establecidos en el POTA". 
Comenzando con el estudio de la modificación del artículo 22.1 de la LOTA, a través de la misma el ejecutivo-legislador pretende resolver las dudas que le suscita la lectura de los artículos 22.3 LOTA en relación con el artículo 22.1 que, en su redacción original, establecía la prevalencia del Plan Andaluz sobre los POT de ámbito subregional y los Planes con Incidencia en la Ordenación del Territorio (PIOT), sin hacer referencia expresa al planeamiento municipal; mientras que, por otro lado, el artículo 23, apartados 1 y 4, de la LOTA establece la prevalencia de los POT sobre los PIOT y el planeamiento municipal y, por último, el artículo 35.3 de la LOUA en el que se dispone que la aprobación sobrevenida de los POT de ámbito subregional supone la prevalencia de sus normas de aplicación directa "cuando éstas sean contrarias o incompatibles con las determinaciones del instrumento de planeamiento urbanístico". Todo ello, pudieran llevar a la conclusión, equivocada a mi juicio, de que sólo las determinaciones de los POT de ámbito subregional prevalecen sobre las disposiciones del planeamiento municipal, prevalencia que, en consecuencia, se negaría cuando dichas normas están contenidas en el POTA ${ }^{59}$.

No obstante, entendemos que tal interpretación literal resulta errónea y debe ser corregida por otra que, incorporé las disposiciones contenidas en el artículo 6 LOTA, que establece que el Plan Andaluz es el marco de referencia territorial para los demás planes regulados en esta ley, lo que supone que todo el planeamiento andaluz está supeditado al POTA. En igual sentido el artículo 162 del POTA establece que la profundización en las estrategias del POTA para la construcción del Modelo Territorial de Andalucía, debe desarrollarse a través de los POT, los PIOT y el planeamiento municipal. En igual sentido, el artículo 2.1, apartado segundo de la LOUA dispone que la "ordenación urbanística se desarrolla en el marco de la ordenación del territorio" por ello el número 3 del artículo 162 del POTA, exige a los POT y PIOT un capítulo expreso de sus memorias que justifique la coherencia de sus propuestas y determinaciones con las estrategias, directrices y recomendaciones del POTA, sin embargo, e ignoramos el motivo, los POT aprobados con anterioridad al POTA no han sufrido ese proceso de adaptación.

Finalmente, y, éste es el argumento de mayor peso, el artículo 20.1 establece el carácter vinculante de los planes territoriales regulados en el artículo 5.1, es decir del POTA y de los Planes de ámbito subregional ${ }^{60}$ y el artículo 21 de la LOTA dispone, al clasificar las determinaciones de los distintos planes terri-

\footnotetext{
${ }^{59}$ Esta parece ser, aún matizada, la opinión de Morillo-Velarde Pérez, J.I. (1994), página 340.

${ }^{60}$ El mismo criterio mantiene Pérez Andrés, A.A. (1998), página 548 a 551.
} 
toriales tres tipos de disposiciones: normas, directrices y recomendaciones, centrados en las primeras, el número 2 del mismo artículo afirma que "las normas son de aplicación directa e inmediata para las Administraciones Públicas y para los particulares, en los suelos urbanizables y no urbanizables". Por tanto, las determinaciones que tengan esta naturaleza contienen mandatos jurídicos perfectos, inmediatamente eficaces, es decir, no precisan de ningún instrumento jurídico de desarrollo ${ }^{61}$, y, este es, sin duda, el carácter, entre otras, de la disposición fijada en el apartado 45 que limita los crecimientos del suelo urbanizable, a la que parece referirse implícitamente la exposición de motivos del Decreto-Ley.

Por tanto, aún admitiendo, que la hermenéutica señalada en primer lugar es correcta, a nuestro juicio, las normas contenidas en el POTA que tengan el carácter de norma deben prevalecer sobre el planeamiento municipal por cuanto, conforme al artículo 22.3 LOTA, citado, las normas del Plan Andaluz se imponen, en definitiva se podría decir que de alguna manera se incorporan o desplazan las previsiones de los POT de ámbito subregional ${ }^{62}$, por lo que una vez ocurrido esto forman parte de los mismos y, no cabe duda que, en base a los preceptos citados, las normas de éstos prevalecen sobre el planeamiento municipal, como afirma Morillo Velarde, esa vinculación es indirecta y mediata ${ }^{63}$.

Por tanto, la modificación comentada, a lo más, añade claridad a nuestro ordenamiento jurídico salvando definitivamente las dudas que pudieran existir.

El número 1 del artículo 3 establece plazos para que se produzca la adaptación propugnada del planeamiento general al POTA y lo hace, con una redacción un tanto confusa, con la que parece remitirse a las normas que sobre la revisión del planeamiento general establezcan los propios planes municipales ${ }^{64}$, de modo que, si el plan general estableció un plazo, por ejemplo, de doce años para su revisión y fue aprobado definitivamente en el año 2002, en el año 2014 debería iniciar la indicada revisión o podría ser objeto de las medidas que inmediatamente comentaremos. De no establecerse plazo para la revisión en el plan general, el Decreto-Ley establece el de ocho años desde la

${ }^{61}$ En igual sentido, puede verse Rebollo Puig, M. y otros (2007), páginas 183 y 184 y Escribano Collado, P. (2008), página 34, aún cuando en página 46 afirma que la norma 45.4.a) no es de aplicación directa a los planes urbanísticos.

62 Ibídem, página 185.

63 Véase Morillo-Velarde Pérez, J.I. (1994), página 340.

${ }^{64}$ En este sentido puede verse la comparecencia del Consejero de Agricultura, Pesca y Medio Ambiente, citada. 
aprobación definitiva del mismo, es decir que un plan aprobado en 2002 tiene obligación de iniciar la revisión desde el día siguiente a la entrada en vigor del Decreto-Ley, es decir desde el 29 de noviembre del 2012.

El problema se plantea a la hora de resolver si dicho plazo de revisión ha transcurrido o no, pues muchos planes generales han dispuesto éste de modo flexible dejando tal decisión al Ayuntamiento, quien decidirá en última instancia y en función de variables que, en ocasiones, no concreta el propio plan si procede o no la revisión por lo que el margen de discrecionalidad de la Corporación municipal es muy amplio ${ }^{65}$. Estos planes, por otro lado, suelen establecer la posibilidad de proceder a la revisión cuando se produzca la vigencia sobrevenida de un POT de ámbito subregional. Lo que no es, sino una reiteración de la previsión legal (artículo 35.3 LOUA).

A la vista de lo anterior, a mi juicio, caben dos interpretaciones posibles, la primera supone entender que una vez transcurrido el plazo mínimo dispuesto en los planes (doce años en los PGOU de Sevilla y Córdoba y ocho años Almería) nace para los Ayuntamientos la obligación de proceder a la revisión, lo que sin duda supone forzar la letra de la norma de revisión contenida en el Plan municipal.

Veamos algunos supuestos concretos: a) el municipio de Huelva, su PGOU aprobado en octubre de 1999 no establece plazo mínimo alguno, sino que remite al acuerdo del Pleno del Ayuntamiento, por tanto siguiendo el primero de los criterios establecidos habrá de entenderse que el Plan no fija plazo para su revisión, en cuyo caso, y de acuerdo con el Decreto-Ley, se debió iniciar la revisión a los ocho años de su aprobación, es decir en 2007. b) El municipio de

${ }^{65}$ Este es el sentido de, por citar sólo algunos de los planes de capitales de provincia, el PGOU de Almería que dice textualmente: "Sin perjuicio de su vigencia indefinida, el límite temporal mínimo a que se refiere el conjunto de las previsiones del Plan General es de ocho (8) años, a contar desde la publicación del acuerdo aprobatorio del mismo. Transcurrido este plazo el Ayuntamiento, en función del grado de realización de sus previsiones, verificará la oportunidad de proceder a revisar el Plan General".

El PGOU de Córdoba, cuyo artículo 1.0.4, establece: "El Ayuntamiento de Córdoba podrá verificar la oportunidad de proceder a la Revisión del presente Plan a los doce (12) años (...)".

El PGOU de Huelva, artículo 4 de la Normativa Urbanística, se establece: "El Ayuntamiento podrá verificar la oportunidad de proceder a la revisión del presente Plan General, en cualquier momento, si se produjera alguna de las siguientes circunstancias ..//..".

El PGOU de Sevilla, artículo 1.1.5, establece: "El Plan General tiene vigencia indefinida mientras no se apruebe su revisión integra que lo sustituya, y sin perjuicio de sus eventuales modificaciones. El horizonte temporal mínimo de sus previsiones programadas es de doce años, debiendo el Ayuntamiento, una vez transcurrido dicho período, verificar la oportunidad de proceder a su revisión parcial o total; .../...”. 
Sevilla, que aprobó su Plan en 2006, y en su articulado se establece un horizonte temporal mínimo para proceder a la revisión de doce años, no tendría obligación de revisarlo hasta 2018.

La segunda opción propuesta consiste, en interpretar que mientras que el Ayuntamiento no considere la oportunidad de revisar el Plan, no nace esta obligación. No obstante son de aplicación las disposiciones de los Planes y LOUA que impone ésta, cuando se produzca la vigencia sobrevenida de un POT de ámbito subregional, obligación que, por lo dicho anteriormente, hay que entender que incluye al POTA, lo que es aún más evidente desde la entrada en vigor del Decreto Ley, con la modificación operada en el artículo 22.1 LOTA.

Esta revisión, sería más respetuosa con la autonomía municipal pues se limitaría a los aspectos del Plan que fueran contradictorias o incompatibles con el POTA, para lo cual, entendemos, sería suficiente con que se tratase de una revisión parcial (artículo 37.2 de la LOUA), siempre que la misma se refiera, exclusivamente, a un conjunto homogéneo de sus determinaciones.

Más dificultades plantea la redacción del párrafo segundo del comentado número 1 del artículo 3. En el mismo se establece que, transcurrido el plazo del párrafo anterior sin que se haya aprobado la revisión, la Consejería competente podrá sustituir la inactividad municipal. Sin embargo, el párrafo primero (el anterior), como acabamos de analizar, no establece plazo para la aprobación de la revisión, sino para el inicio de procedimiento de revisión, lo que es muy diferente. Este es, por otro lado, el sentido del artículo 36.3 de la LOUA al que se remite el precepto comentado, al disponer que la Consejería debe requerir al Ayuntamiento especificando el contenido y alcance de la obligación legal a cumplir y dando plazo para su cumplimiento, "Transcurrido ese plazo (...) podrá sustituir la inactividad municipal relativa a la formulación del correspondiente proyecto (...)". En consecuencia la Consejería deberá velar porque transcurridos los plazos establecidos en el párrafo primero del número 1 del artículo 3 del Decreto-Ley, se inicie por los Ayuntamientos el procedimiento de revisión de su planeamiento general y éste siga unos cauces y plazos razonables, en caso contrario, podrá realizar el requerimiento que acabamos de referir.

Esta ha de ser, igualmente, la interpretación del número 2 del meritado artículo $3^{\circ}$. En él se establece una medida excepcional para los Ayuntamientos, al limitar su potestad de planeamiento en el supuesto de que no se haya aprobado la revisión una vez transcurrido el plazo previsto para ello. Por ello, su in- 
terpretación ha de limitarse a los supuestos expresamente previstos en la norma. Razón por la cual, consideramos que los plazos que deben transcurrir son: a) el indicado en el número 1 para iniciar la revisión del planeamiento general y, b) el plazo de tramitación del indicado plan hasta llegar a su aprobación definitiva.

Esta interpretación, por otro lado, no limita la eficacia inmediata de las normas del POTA, objetivo pretendido por el Decreto-Ley, pues como hemos mantenido y, en virtud de lo dispuesto en los artículos 22.1 LOTA (modificado) y, 35.3 LOUA, las normas de aplicación directa del Plan Andaluz prevalecen sobre las del planeamiento urbanístico, incluida, claro está, la norma 45.4 del POTA, otra cosa será que la misma, por la forma en que está redactada, imponga de forma directa e inmediata sin mediación de una revisión del Plan general, límites al crecimiento cuando estos sean superiores al $40 \%$ del suelo urbano existente y/o al 30\% de la población en un espacio temporal de ocho años.

\section{BIBLIOGRAFÍA}

ACOSTA BONO, Gonzalo (1999), «Ordenación del litoral y política territorial en Andalucía», Actas de las jornadas sobre el litoral celebradas en Almería.

ARANA GARCÍA, Estanislao y TORRES LÓPEZ, Ma Asunción (2009), " "La gestión integrada de zonas costeras en Andalucía". En la obra colectiva "Estudios sobre ordenación, planificación y gestión del litoral". Dirigida por Francisco Javier Sanz Larruga», editorial Fundación Pedro Barrié de la Maza.

ASTARLOA HUARTE-MANDIOGA, Ignacio (1985), «Teoría y práctica del Decreto-Ley en el ordenamiento español», Revista de Administración Pública, número 106.

BARREIRO GONZÁLEZ, Germán José (2003), «Sobre la extraordinaria y urgente necesidad de los Decretos-Leyes», Revista de Derecho Privado y Constitución, número 51.

ESCRIBANO COLLADO, Pedro (2008), «Ordenación del Territorio y Principio de Legalidad: El Plan de Ordenación del Territorio de Andalucía. En la obra colectiva "El Derecho Urbanístico del siglo XXI. Libro en homenaje al Profesor Martín Bassols Coma". Dirigida por Carlos Rogel Vide y Martín Bassols Coma» Tomo III, editorial Reus. 
GONZÁLEZ GARCÍA, Julio y ZAMBONINO PULITO, María (2010), «"El derecho de costas y la distribución constitucional de competencias entre el Estado y las Comunidades Autónomas. Cuestiones recurrentes y controversias nuevas". En la obra colectiva "El derecho de costas en España". Dirigida por Enrique Sánchez Goyanes», editorial La Ley.

HERRÁIZ SERRANO, Olga (2011), «Teoría y práctica del decreto-ley autonómico tras su incorporación al sistema de fuentes de algunas comunidades», Anuario de Derecho Parlamentario, número 25.

JAQUENOD DE ZSÖGÖN, Silvia (2008), «Sistemas naturales y jurídicos», editorial Dykinson.

LÓPEZ MENUDO, Francisco (1990), «Directrices Regionales del Litoral de Andalucía», Revista Andaluza de Administración Pública, número 3.

LÓPEZ MENUDO, Francisco (1990), «Bases para la ordenación del territorio de Andalucía», Revista Andaluza de Administración Pública, número 4.

MEDINA GUERRERO, Manuel (2010), «El control parlamentario del Decreto Ley», Revista Andaluza de Administración Pública, número 77.

MORILLO-VELARDE PÉREZ, José Ignacio (1989), «El Decreto-Ley en la Constitución y en la jurisprudencia constitucional en la obra colectiva Libro homenaje al profesor José Luis Villar Palasí. Coordinado por Rafael Gómez-Ferrer Morant», editorial Civitas.

MORILLO-VELARDE PÉREZ, José Ignacio (1994), «La Ley de Ordenación del Territorio de Andalucía», Revista Andaluza de Administración Pública.

MUÑOZ MACHADO, Santiago (2006), «Tratado de Derecho Administrativo y Derecho Público general. Tomo II», editorial Iustel.

NÚÑEZ LOZANO, $\mathrm{M}^{\mathrm{a}}$ Carmen (2003), «El Decreto-Ley como alternativa a la potestad reglamentaria en situaciones de extraordinaria y urgente necesidad», Revista de Administración Pública, número 162.

NÚÑEZ LOZANO, Ma Carmen y ZAMORANO WISNES, José (2012), «Ordenación de los espacios marítimos, gestión integrada de las zonas 
costeras y planificación hidrológica», comunicación presentada al I Congreso Iberoamericano de Gestión Integrada de Áreas Litorales; Cádiz 25 al 27 de enero de 2012.

ORTIZ DÍAZ, José (1990), «Ordenación del territorio y del litoral en Andalucía», Revista Andaluza de Administración Pública, número 3.

PAREJO NAVAJAS, Teresa (2011), «La proyección de la ordenación física de usos sobre la costa y el mar próximo: la planificación del aquitorio», editorial IUSTEL.

PÉREZ ANDRÉS, Antonio Alfonso (1998), «La ordenación del territorio en el Estado de las Autonomías», editorial Marcial Pons.

PULIDO QUEVEDO, Manuel (2005), «La apreciación de la urgencia y necesidad en los Decretos leyes», revista Aranzadi Tribunal Constitucional, número 20.

RAMALLO MASSANET, Juan (2003), «El Decreto-Ley en materia tributaria», revista de Derecho Privado y Constitución, número 17.

REBOLLO PUIG, Manuel (2007), “"Derecho urbanístico y ordenación del territorio en Andalucía". En la obra colectiva del mismo nombre. Coordinada por Manuel Rebollo Puig» editorial: Iustel.

REBOLLO PUIG, Manuel (2008), «"El Derecho propio de Andalucía y sus fuentes". En la obra colectiva "Comentarios al Estatuto de Autonomía para Andalucía". Dirigida por Santiago Muñoz Machado y Manuel Rebollo Puig», editorial Thomson-Givitas.

SALAS HERNÁNDEZ, Javier (1979), «Los Decretos-Leyes en la Constitución española de 1978», editorial Civitas.

SANZ LARRUGA, Francisco Javier (2010), «"Estado compuesto e iniciativas y estrategias sobre la ordenación y gestión del litoral en las Comunidades Autónomas". En la obra colectiva "El Derecho de Costas en España". Dirigida por Enrique Sánchez Goyanes», editorial La Ley.

SANZ LARRUGA, Francisco Javier (2010), «"España y la gestión integrada de las costas en el marco del ordenamiento internacional sobre protección 
del mar mediterráneo y de la política ambiental y marítima de la Unión Europea". en la obra colectiva "El Derecho de Costas en España". Dirigida por Enrique Sánchez Goyanes», editorial La Ley.

ZAMBONINO PULITO, María (1996), «"El mar. Dominio Público Marítimo Terrestre y Medio Marino". En la obra colectiva "El Derecho de los Bienes Públicos". Dirigida por Julio González García», editorial Tirant lo Blanch, segunda edición.

ZAMORANO WISNES, José (2013), «Ordenación del litoral. Una propuesta de gestión integrada», editorial La Ley. 